\title{
Pemahaman Siswa Kelas XI SMK Negeri 1 Pujer Dalam Menyelesaikan Soal AKM Numerasi
}

Author:
Ageng Jelly Purwanto
Affiliation:
'SMK Negeri 1 Pujer,
Bondowoso, East Java,
Indonesia
Corresponding author:
Ageng Jelly Purwanto,
agengjelly@ gmail.com
Dates:
Received: 15/4/2021
Accepted: 1/7/2021
Published: 9/7/2021

\section{Author:}

Affiliation:

${ }^{1}$ SMK Negeri 1 Pujer, Bondowoso, East Java, Indonesia

Corresponding author:

Ageng Jelly Purwanto, agengjelly@gmail.com

\section{Dates:}

Received: $15 / 4 / 2021$

Accepted: $1 / 7 / 2021$

Published: 9/7/2021

\begin{abstract}
Abstrak. Ujian Nasional (UN) telah diganti menjadi Asesmen Nasional (AN) oleh Kementrian Pendidikan dan Kebudayaan. AN adalah asesmen yang dilakukan untuk pemetaan mutu pendidikan pada semua sekolah. Di dalam AN itu ada tiga instrumen, salah satunya Asesmen Kompetensi Minimum (AKM). AKM Numerasi adalah kemampuan berpikir menggunakan konsep, prosedur, fakta, dan alat matematika untuk menyelesaikan masalah sehari-hari pada berbagai jenis konteks yang relevan untuk individu sebagai warga negara Indonesia dan Dunia. Metode yang digunakan dalam penelitian ini adalah metode penelitian deskriptif kualitatif. Data yang dihasilkan dalam penelitian ini berupa hasil tes dan wawancara. Sumber data utama dalam penelitian ini adalah siswa kelas XI SMK Negeri 1 Pujer. Hasil dari penelitian ini adalah pemahaman siswa kelas XI SMK Negeri 1 Pujer masih rendah, hal tersebut ditunjukkan oleh hasil penyelesaian tes yang belum mencapai $50 \%$ dari total seluruh siswa, sehingga perlu lebih banyak dikenalkan model-model soal AKM khususnya Numerasi kepada siswa
\end{abstract}

Kata kunci: AKM, Numerasi, Pemahaman

\begin{abstract}
The National Examination (UN) has been changed to National Assessment (AN) by the Ministry of Education and Culture. AN is an assessment carried out to map the quality of education in all schools. There are three instruments in the AN, one of which is the Minimum Competency Assessment (AKM). AKM Numeration is the ability to think using mathematical concepts, procedures, facts, and tools to solve everyday problems in various types of contexts that are relevant to individuals as citizens of Indonesia and the world. The method used in this research is descriptive qualitative research method. The data generated in this study are in the form of test results and interviews. The main data source in this study were 11th grade students of SMK Negeri 1 Pujer. The result of this research is that the students' understanding 11th grade students of XI SMK Negeri 1 Pujer is still low, this is indicated by the results of the completion of the test that have not reached $50 \%$ of the total students, so it is necessary to introduce more AKM question models, especially Numeration to students.
\end{abstract}

Keywords: AKM, Numeration, Understanding

\section{JoMEaL}

\section{Copyright:}

This work is licensed under a Creative Commons Attribution-ShareAlike 4.0 International License.

\section{Read online:}

https://jurnal.unej.ac.id/index.php/JOMEAL/index or scan barcode beside.

\section{How to cite this article:}

Purwanto, A. (2021). Pemahaman Siswa Kelas XI SMK Negeri 1 Pujer dalam Menyelesaikan Soal AKM Numerasi. Journal of Mathematics Education and Learning, 1(2), 109-115. Retrieved from https://jurnal.unej.ac.id/index. php/JOMEAL/article/view/24272 


\section{Pendahuluan}

Ujian Nasional (UN) telah diganti menjadi Asesmen Nasional (AN) oleh Kementerian Pendidikan dan Kebudayaan (Kemendikbud). AN nantinya dimulai pada 2021 atau menjadi AN 2021. Bagi siswa, tentu harus paham tentang asesmen nasional. AN adalah asesmen yang dilakukan untuk pemetaan mutu pendidikan pada semua sekolah, madrasah, serta program kesetaraan jenjang dasar dan menengah. Di dalam asesmen nasional itu ada tiga instrumen, yaitu, 1. Asesmen Kompetensi Minimum (AKM), 2. Survei karakter, 3. Survei lingkungan belajar (Kemendikbud, 2020).

Hal penghapusan UN menjadi masalah baru pada pendidikan khususnya bagi guru. Hal-hal yang dapat menjadi masalah tersebut, yaitu 1) adanya perspektif guru-guru yang berbeda, yaitu pro ataupun kontra dengan kebijakan penghapusan UN yang diganti menjadi AKM dan survei karakter, 2) adanya ketidaksiapan guru dalam menjalankan kebijakan baru, dan 3) keraguan kualitas akan alat ukur asesmen kompetensi minimum dan survei karakter (Sani, 2020).

AKM merupakan penilaian kompetensi mendasar yang diperlukan oleh semua siswa untuk mampu mengembangkan kapasitas diri dan berpartisipasi positif pada masyarakat. Terdapat dua kompetensi mendasar yang diukur AKM yaitu literasi membaca dan literasi matematika (numerasi). Baik pada literasi membaca dan numerasi, kompetensi yang dinilai mencakup keterampilan berpikir logis-sistematis, keterampilan bernalar menggunakan konsep serta pengetahuan yang telah dipelajari, serta keterampilan memilah serta mengolah informasi. AKM menyajikan masalah-masalah dengan beragam konteks yang diharapkan mampu diselesaikan oleh siswa menggunakan kompetensi literasi membaca dan numerasi yang dimilikinya. AKM dimaksudkan untuk mengukur kompetensi secara mendalam, tidak sekadar penguasaan konten.

Literasi membaca didefinisikan sebagai kemampuan untuk memahami, menggunakan, mengevaluasi, dan merefleksikan berbagai jenis teks tertulis. Tentu untuk mengembangkan kapasitas individu sebagai warga Indonesia dan warga dunia, juga untuk dapat berkontribusi secara produktif kepada masyarakat sedangkan numerasi adalah kemampuan berpikir menggunakan konsep, prosedur, fakta, dan alat matematika untuk menyelesaikan masalah sehari-hari pada berbagai jenis konteks yang relevan untuk individu sebagai warga negara Indonesia dan Dunia (Puspendik, 2020). Numerasi lebih menekankan pada proses matematis.

Soal AKM sangat berbeda dengan soal UN. Berikut ini merupakan 5 bentuk soal AKM. (1) Pilihan ganda: memilih satu jawaban benar dari tiap soal. (2) Pilihan ganda kompleks: memilih lebih dari satu jawaban benar dalam satu soal. (3) Menjodohkan: menjawab dengan menarik garis dari satu titik ke titik lainnya yang merupakan pasangan pertanyaan dengan jawabannya. (4) Isian singkat: menjawab berupa bilangan, kata untuk menyebutkan nama benda, tempat, atau jawaban pasti lainnya. (5) Uraian: menjawab soal berupa kalimat-kalimat untuk menjelaskan jawabannya (Purwanto, 2020). Soal AKM didesain menggunakan stimulus dengan konteks yang beragam misalnya dengan menyajikn informasi berupa tulisan, tabel, grafik dan ilustrasi (Sani, 2021).

AKM merupakan hal baru bagi siswa semua jenjang khususnya SMK. AKM perlu sering dilatihkan pada siswa khususnya AKM numerasi karena berkaitan erat dengan mata pelajaran matematika. Sehingga penelitian ini bertujuan untuk melihat bagaimana pemahaman siswa kelas XI SMK Negeri 1 Pujer dalam menyelesaiakan soal bentuk AKM Numerasi. Kelas XI SMK Negeri 1 Pujer memiliki tiga kompetensi keahlian yaitu Teknik Kendaraan Ringan Otomotif, Teknik dan Bisnis Sepeda Motor serta Bisnis Daring dan Pemasaran. Siswa kelas XI dari ketiga program keahlian 
tesebut yang akan menjadi calon peserta AN 2021. Menurut Purwanto (2021) siswa SMK Negeri 1 Pujer belum terbiasa mengerjakan soal model AKM.

\section{Metode Penelitian}

Metode yang digunakan dalam penelitian ini adalah metode penelitian deskriptif kualitatif. Metode ini dipilih karena dalam penelitian ini lebih mementingkan proses siswa dalam menyelesaikan suatu masalah yang dihadapinya dari pada hasil yang diperoleh. Penelitian ini menggunakan jenis penelitian studi kasus yaitu penelitian yang didalamnya peneliti menyelidiki secara cermat suatu aktivitas dan proses yang dikumpulkan secara lengkap dengan menggunakan berbagai prosedur pengumpulan data berdasar waktu yang telah ditentukan (Creswell, 2009). Satori, D. (2011) mengungkapkan bahwa penelitian kualitatif dilakukan karena peneliti ingin mengeksplor fenomena-fenomena yang tidak dapat dikuantifikasikan yang bersifat deskriptif seperti proses suatu langkah kerja, formula suatu resep, pengertian-pengertian tentang suatu konsep yang beragam, karakteristik suatu barang dan jasa, gambargambar, gaya-gaya, tata cara suatu budaya, model fisik suatu artifak dan lain sebagainya. Selain itu, Sugiono (2012) juga mengemukakan penelitian kualitatif sebagai metode penelitian yang berlandaskan pada filsafat postpositivisme, digunakan untuk meneliti pada kondisi objek alamiah, dimana peneliti adalah sebagai instrumen kunci, teknik pengumpulan data dengan triangulasi, analisis data bersifat induktif atau kualitatif, dan hasil penelitian kualitatif lebih menekankan makna daripada generalisasi. Menurut Nana Syaodih Sukmadinata, S. (2011), penelitian deskriptif kualitatif ditujukan untuk mendeskripsikan dan menggambarkan fenomenafenomena yang ada, baik bersifat alamiah maupun rekayasa manusia, yang lebih memperhatikan mengenai karakteristik, kualitas, keterkaitan antar kegiatan.

Data yang ingin dihasilkan dalam penelitian ini berupa tulisan dan dalam bentuk transkrip. Data yang berupa tulisan diperoleh dari hasil tes dan pengamatan, sedangkan data dalam bentuk transkrip diperoleh melalui wawancara. Sumber data utama dalam penelitian ini adalah siswa kelas XI SMK Negeri 1 Pujer Kompetensi keahlian Teknik Kendaraan Ringan Otomotif, Teknik dan Bisnis Sepeda Motor serta Bisnis Daring dan Pemasaran yang menjadi subjek penelitian. Pengambilan kelas XI sebagai subjek karena AKM diujikan untuk siswa kelas XI pada jenjang SMK/SMA, dengan jumlah subjek penelitian sebagai berikut.

Tabel 1. Jumlah subjek penelitian

\begin{tabular}{|c|c|c|c|c|}
\hline \multirow{2}{*}{ No } & \multirow{2}{*}{ Kelas } & \multicolumn{3}{|c|}{ Jumlah } \\
\cline { 3 - 5 } & & L & P & Total \\
\hline 1 & XI BDP & 9 & 7 & 16 \\
\hline 2 & XI TKRO & 24 & 0 & 24 \\
\hline 3 & XI TBSM & 26 & 0 & 26 \\
\hline
\end{tabular}

Tahapan penelitian ini diawali dengan pembuatan soal AKM Numerasi, soal dibuat oleh peneliti dengan divalidasi oleh guru Matematika dan guru Bahasa Indonesia SMK Negeri 1 Pujer. Validasi oleh guru Matematika berkaitan dengan numerasi sedangkan validasi oleh guru Bahasa Indonesia berkaitan dengan tata bahasa yang digunakan. Setelah soal divalidasi, dilanjutkan dengan pemberian tes pada siswa kelas XI SMK Negeri 1 Pujer Kompetensi keahlian Teknik Kendaraan Ringan Otomotif, Teknik dan Bisnis Sepeda Motor serta Bisnis Daring dan Pemasaran dan dilanjutkan dengan wawancara. 


\section{Hasil dan Pembahasan}

Langkah kerja yang dilakukan dalam penelitian ini meliputi penyusunan soal AKM Numerasi dengan mengambil tema jarak yang berkaitan dengan mata pelajaran Fisika dan Matematika. Pengambilan tema ini disesuaikan dengan pemahaman siswa tentang jarak dianggap mampu karena siswa terbiasa mengendarai motor. Selain itu didukung oleh dua bidang keahlian otomotif yaitu kompetensi keahlian teknik kendaraan ringan otomotif serta teknik dan bisnis sepeda motor yang setiap mata pelajaran bidang produktif selalu berkaitan dengan kendaraan. Berikut soal bentuk AKM Numerasi.

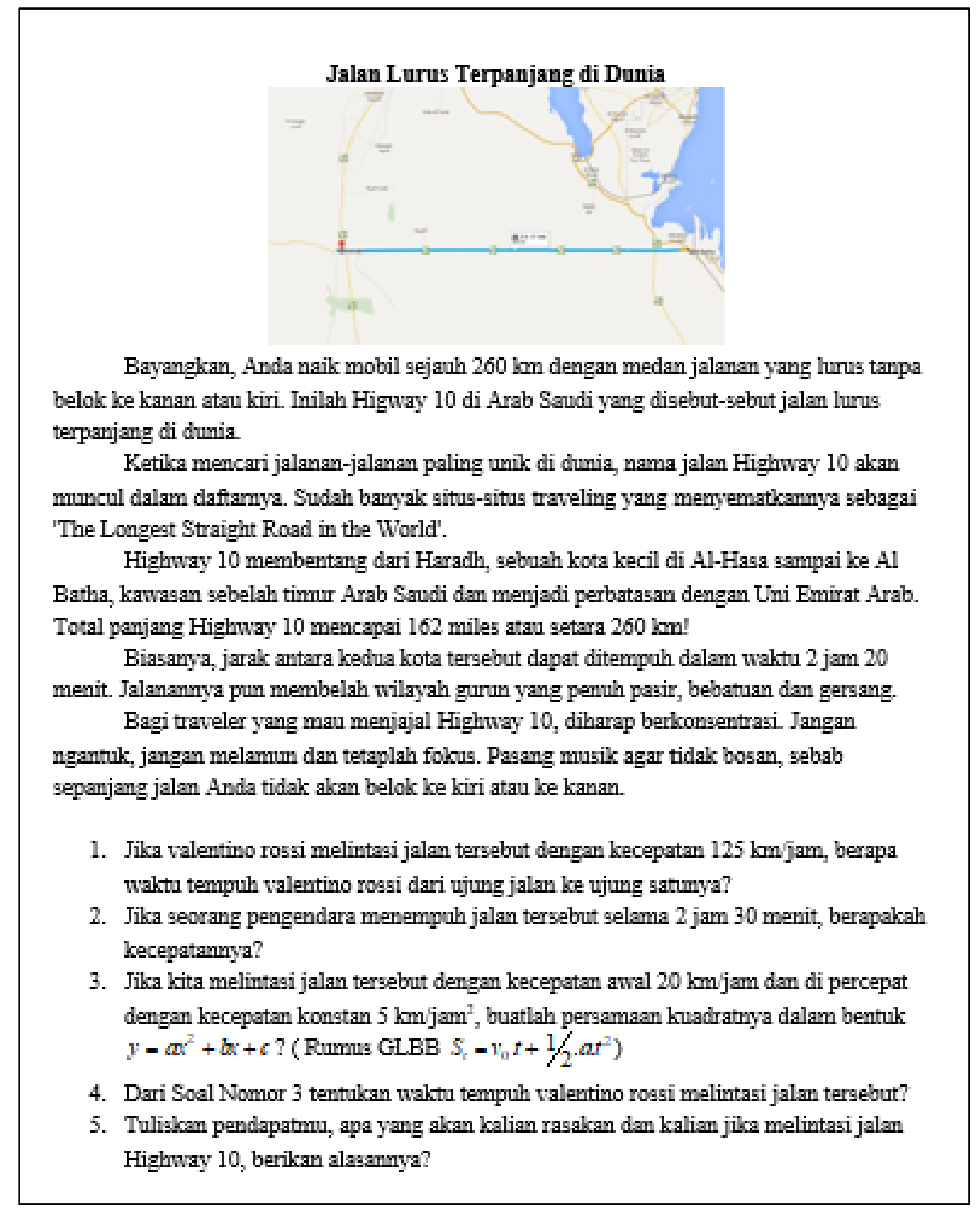

Gambar 1. Soal AKM Numerasi

Ilustrasi dari soal AKM Numerasi tesebut diambil dari kehidupan nyata yaitu jalan lurus terpanjang di dunia yang terletak di Arab Saudi (kumparan.com). Dari soal AKM Numerasi yang sudah dibuat oleh peneliti dan divalidasi oleh guru Matematika dan guru Bahasa Indonesia, dilanjutkan dengan pemberian tes pada siswa kelas XI SMK Negeri 1 Pujer Kompetensi keahlian Teknik Kendaraan Ringan Otomotif, Teknik dan Bisnis Sepeda Motor serta Bisnis Daring dan Pemasaran. Pemberian tes dilakukan secara langsung kepada siswa kelas XI SMK Negeri 1 Pujer Kompetensi keahlian Teknik Kendaraan Ringan Otomotif, Teknik dan Bisnis Sepeda Motor serta 
Bisnis Daring dan Pemasaran. Tes dilakukan tanpa berbasis komputasi tapi menggunakan paper, tujuannya agar peneliti dapat melihat apapun yang dituliskan siswa pada lembar jawab. Skor maksimal dalam tes ini adalah 100 dengan KKM 60. KKM 60 digunakan karena sudah sesuai yang disajikan dalam e-rapr SMK dan pedoman penilaian SMK tahun 2019. Siswa dianggap tuntas jika memperoleh skor minimum 60. Berikut salah satu jawaban siswa

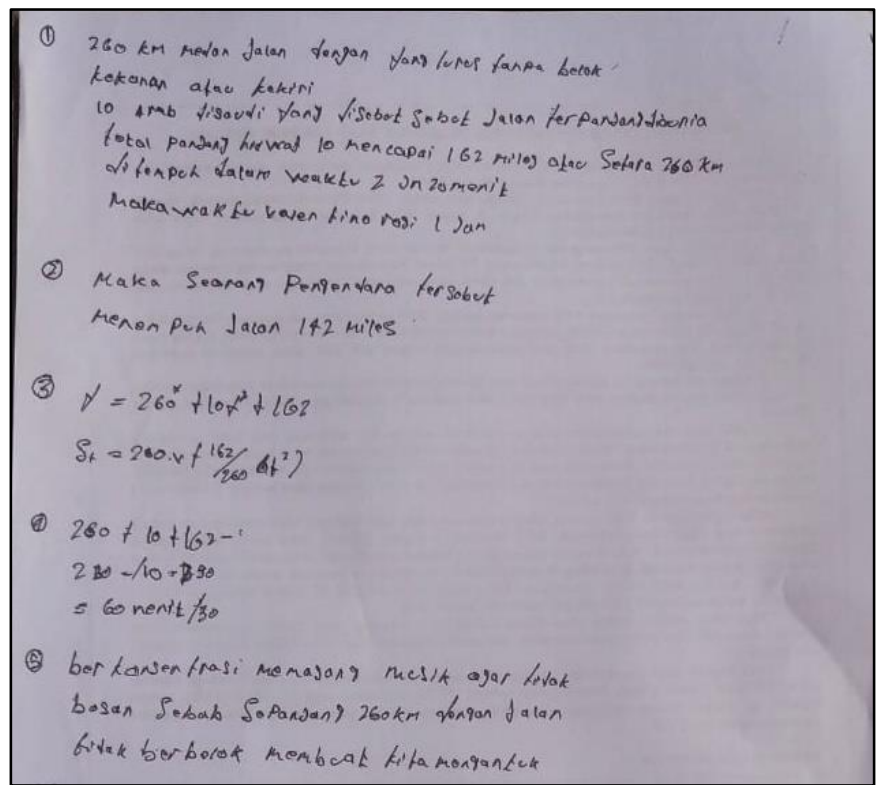

Gambar 2. Jawaban siswa yang tuntas

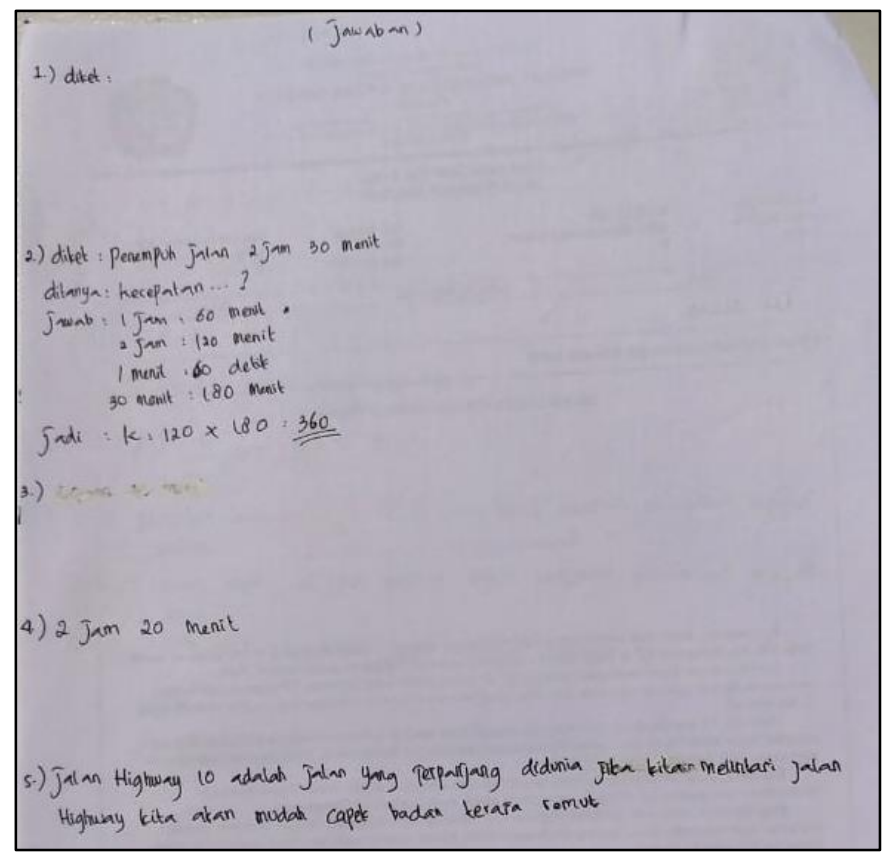

Gambar 3. Jawaban siswa yang tidak tuntas

Dari data hasil jawaban siswa yang belum tuntas dapat dilihat bahwa pemahaman siswa dalam menyelesaikan soal AKM Numerasi belum maksimal karena beberapa soal belum mampu terjawab oleh siswa, sedangkan siswa yang tuntas sudah bisa menyelesaikan soal dengan baik. Dari proses ini diperoleh data hasil tes berupa skor dan hasil pengamatan tentang bagaimana siswa berproses dalam menyelesaikan soal AKM Numerasi. Berikut skor perolehan siswa setelah melalui proses analisa. 
Tabel 2. Skor perolehan hasil tes siswa

\begin{tabular}{|c|c|c|c|c|}
\hline \multirow{2}{*}{ No } & \multirow{2}{*}{ Kelas } & Tuntas & $\begin{array}{c}\text { Jumlah } \\
\text { Tidak } \\
\text { tuntas }\end{array}$ & $\begin{array}{c}\text { Persentase } \\
\text { Tuntas }\end{array}$ \\
\hline 1 & XI BDP & 5 & 11 & $31 \%$ \\
\hline 2 & XI TKRO & 4 & 20 & $17 \%$ \\
\hline 3 & XI TBSM & 6 & 20 & $23 \%$ \\
\hline
\end{tabular}

Dari hasil tes yang menunjukkan rendahnya pemahaman siswa ditunjukkan dengan skor ketuntasan yang kurang dari 50\% dan wawancara kepada beberapa siswa yang tuntas dan tidak tuntas dari ketiga program keaglian diperoleh beberapa kesulitan siswa dalam memahami dan menyelesikan soal AKM Numerasi. Beberapa kesulitan yang ditemui siswa adalah sebagai berikut (1) Siswa cenderung malas membaca tekt yang panjang, (2) Siswa kesulitan menterjemahkan dalam bahasa matematika, (3) pemahaman siswa tentang materi yang disajikan masih kurang, (4) siswa belum terbiasa dengan soal level pengetahuan analisis, (5) siswa belum mampu meramu semua informasi yang diberikan dalam bacaan, (6) pemahaman siswa tentang informasi diluar mata pelajaran masih kurang, (7) siswa masih kebingungan bagaimana memulai mengerjakan soal.

Dari penelitian ini diperoleh beberapa temuan yaitu sebagai berikut, (1) Soal AKM merupakan hal baru bagi guru dan siswa, (2) guru maupun siswa masih menemukan banyak kendala dalam memahami soal AKM khususnya Numerasi, (3) perlu pelatihan khusus untuk guru dalam menyusun soal AKM Numerasi. Karena AKM diundur sampai September - Oktober 2021(tribunnews.com) maka sekolah dapat menyiapkan siswa untuk lebih mengenal dan memahami AKM.

\section{Kesimpulan}

Simpulan dari penelitian ini adalah pemahaman siswa kelas XI SMK Negeri 1 Pujer dalam menyelesaikan AKM Numerasi masih rendah, hal tersebut ditunjukkan oleh hasil penyelesaian tes yang belum mencapai 50\% dari total seluruh siswa dan hasil wawancara yang menunjukkan kesulitan siswa dalam memahami soal AKM Numerasi, sehingga perlu lebih banyak dikenalkan model-model soal AKM khususnya Numerasi kepada siswa.

\section{Daftar Pustaka}

Bachtiar, A. (2020). Jalan lurus terpanjang di bumi, 240 kilometer tanpa pemandangan segar. Retrieved 11 March, 2021, from https://kumparan.com/absal-bachtiar/jalan-lurus-terpanjangdi-bumi-240-kilometer-tanpa-pemandangan-segar-1u1mFiJIm3F/full.

Cresswell, J.W. (2009). Research Design (Third Edition). California: SAGE Publication.Inc.

DitPSMK. (2018). Panduan penilaian hasil belajar dan pengembangan karakter pada Sekolah Menengah Kejuruan. Jakarta: Direktorat Pembinaan Sekolah Menengah Kejuruan.

DitPSMK. (2019). Panduan penggunaan e-rapor SMK 5.0.0. Jakarta: Direktorat Pembinaan Sekolah Menengah Kejuruan.

Kemendikbud. (2020). Asesmen Nasional sebagai penanda perubahan paradigma evaluasi pendidikan, $\quad$ Retrieved $17 \quad$ December, $\quad 2020, \quad$ from https://www.kemdikbud.go.id/main/blog/2020/10/asesmen-nasional-sebagaipenandaperubahan-paradigma-evaluasi-pendidikan. 
Kurniawan, G. (2021). Asesmen nasional diundur ke September - Oktober 2021. Retrieved 12 May, 2021, from https://m.tribunnews.com/pendidikan/2021/01/21/asesmen-nasional-diundur-keseptember-oktober-2021-apa-itu-asesmen-nasional.

Purwanto, A. J. (2020). Tryout Assesment Kompetensi Minimum (AKM). Retrieved 06 May, 2021, from https://www.farazka.my.id/.

Purwanto, A. J. (2020). Materi semester ganjil. Retrieved July 1, 2020, from https://www.farazka.com/.

Purwanto, A.J. (2021). Pemanfaatan web blog sebagai media pembelajaran matematika di SMK Negeri 1 Pujer Tahun Pelajaran 2020/2021. Saintifika, [S.1.], v. 23, n. 1, p. 32-37.

Puspendik. (2021). Asesmen Kompetensi minimum. Retrieved 06 May, 2021, from https://hasilun.puspendik.kemdikbud.go.id/akm/.

Sani, R.A. (2021). Pembelajaran Berorientasi AKM. Jakarta: Bumi Aksara.

Sari, A., Daulay, S., Yuliani, Y., \& Epriani, P. (2020). Penghapusan Ujian Nasional Tahun 2021 dalam perspektif guru SMA di Kota Tebing Tinggi. Prosiding Seminar Nasional PBSI-III Tahun 2020, 213-220.

Satori, D. \& Komariah, A. (2011). Metodologi penelitian kualitatif. Bandung: Alfabeta.

Sugiyono. (2012). Metode penelitian kuantitatif, kualitatif, dan R\&D. Bandung: Alfabeta.

Sukmadinata, N.S. (2011). Metode penelitian pendidikan. Bandung: Remaja Rosdakarya. 